\title{
Spinal ependymoma complicated by superficial siderosis
}

\author{
Reuben Grech, Leo Galvin, Seamus Looby, John Thornton
}

Department of Neuroradiology, Beaumont Hospital, Dublin, Ireland

\section{Correspondence to Dr Reuben Grech,} reubengrech@yahoo.com

\section{DESCRIPTION}

A 64-year-old woman presented with progressive hearing loss. A pure-tone audiography confirmed bilateral high-frequency sensorineural hearing loss. Her medical and surgical history was unremarkable except for long-standing back pain. Neurological examination revealed mild dysmetria and gait ataxia. There was no leg weakness or sphincteric dysfunction.

MRI revealed superficial siderosis lining the cerebellum and brainstem, which prompted further imaging of the entire neuraxis in order to exclude an underlying cause. A myxopapillary ependymoma seen at the level of the conus medullaris was felt to be responsible for recurrent haemorrhage within the subarachnoid space.

Excision of the spinal ependymoma was performed and the patient regained near-normal hearing following a cochlear implant.

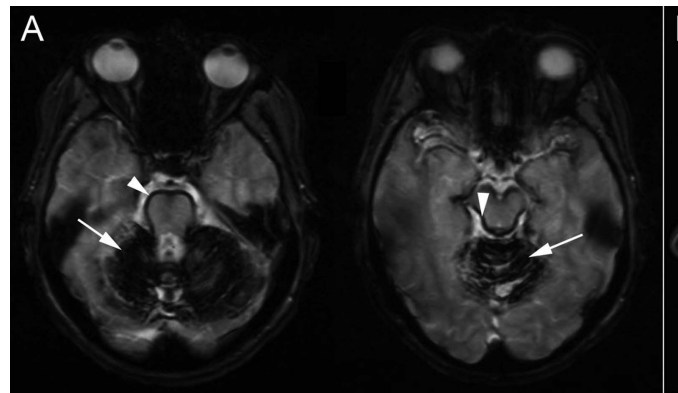

\section{DISCUSSION}

Superficial siderosis presents with slowly progressive sensorineural hearing loss, gait ataxia and cerebellar dysarthria. Involvement of other cranial nerves has also been described. Clinical history and examination often suggest a neurodegenerative disorder.

Superficial siderosis results from haemosiderin deposition in the subpial layers of the neuraxis, and complicates chronic haemorrhage within the subarachnoid space. The posterior fossa is preferentially affected, which may in part be explained by the presence of Bergmann glia in the cerebellum that display increased ferritin synthesis. ${ }^{2}$ The long glial segment of the vestibulocochlear nerve makes it more vulnerable to axonal damage by iron deposition. ${ }^{1}$ Bilateral sensorineural hearing loss is present in $95 \%$ of affected individuals. ${ }^{3}$

Figure 1 Linear hypointensity is seen along the cerebellar folia and superior vermis on the axial gradient echo images $(A)$ compatible with extensive haemosiderin deposition. There is also hypointense lining of the midbrain tectum and pons. The sagittal T1-weighted image (B) reveals low signal intensity of the upper cerebellum due to extensive haemosiderin preferentially deposited in the upper cerebellum and superior vermis. The linear hypointensities are also appreciated on the axial T2 sequence (C) where they clearly outline the cerebellar folia and ventral pons and reflect the characteristic subpial haemosiderin deposition. Mild underlying cerebellar atrophy is also appreciated. The radiological findings are pathognomonic of superficial siderosis.

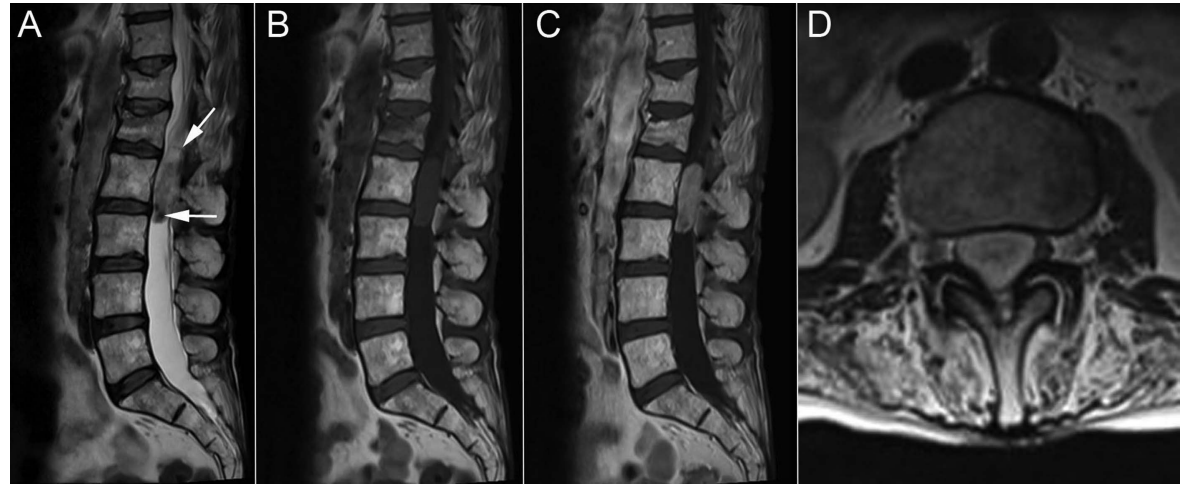

To cite: Grech R, Galvin L Looby S, et al. BMJ Case Rep Published online: [please include Day Month Year] doi:10.1136/bcr-2013201036

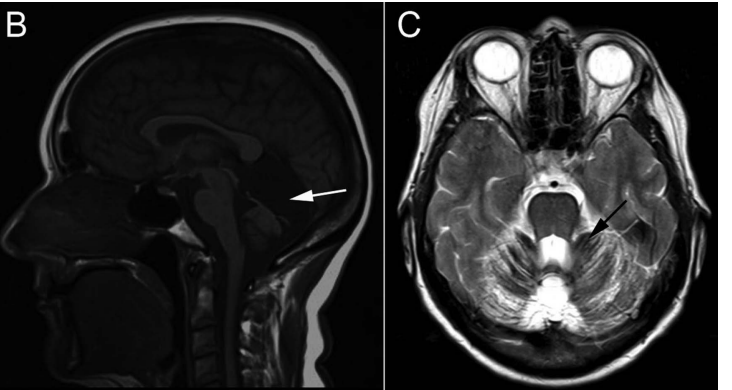

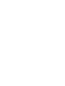


MRI is the investigation of choice. T2-weighted imaging reveals linear hypointensity outlining the brainstem, cerebellar folia (figure 1) and the pial surface of the cord. Less commonly haemosiderin deposition is seen lining the Sylvian fissures, the cerebral sulci and cauda equina roots. Gradient echo imaging is exquisitely sensitive as the haemosiderin produces blooming artefacts. Imaging of the entire neuraxis should be performed to rule out underlying neoplasms, arteriovenous malformations/fistulas and dural defects.

Superficial siderosis complicating spinal ependymoma has been reported in the literature. ${ }^{3}$ Ependymomas present as soft, encapsulated 'sausage-like' masses with a propensity to haemorrhage (figure 2). Blood products may produce a characteristic intratumoral 'cap sign' or spill within the subarachnoid compartment.
Competing interests None.

Patient consent Obtained.

Provenance and peer review Not commissioned; externally peer reviewed

\section{REFERENCES}

1 Kumar N, Cohen-Gadol AA, Wright RA, et al. Superficial siderosis. Neurology 2006;66:1144-52.

2 Kumar N. Neuroimaging in superficial siderosis: an in-depth look. AJNR Am J Neuroradiol 2010;31:5-14.

3 Spengos K, Vassilopoulou S, Tsivgoulis G, et al. Superficial siderosis due to a lumbar ependymoma mimicking adult-onset spinocerebellar ataxia. Clin Neurol Neurosurg 2007; 109:705-7.

\section{Learning points}

- Superficial siderosis presents with slowly progressive sensorineural hearing loss, gait ataxia and cerebellar dysarthria.

- Superficial siderrosis complicates chronic haemosiderin deposition in the subpial layers of the neuraxis and the imaging findings are characteristic.

Imaging of the entire neuraxis should be carried out to exclude underlying neoplasia.

Copyright 2013 BMJ Publishing Group. All rights reserved. For permission to reuse any of this content visit http://group.bmj.com/group/rights-licensing/permissions.

BMJ Case Report Fellows may re-use this article for personal use and teaching without any further permission.

Become a Fellow of BMJ Case Reports today and you can:

- Submit as many cases as you like

- Enjoy fast sympathetic peer review and rapid publication of accepted articles

- Access all the published articles

- Re-use any of the published material for personal use and teaching without further permission

For information on Institutional Fellowships contact consortiasales@bmjgroup.com

Visit casereports.bmj.com for more articles like this and to become a Fellow 